
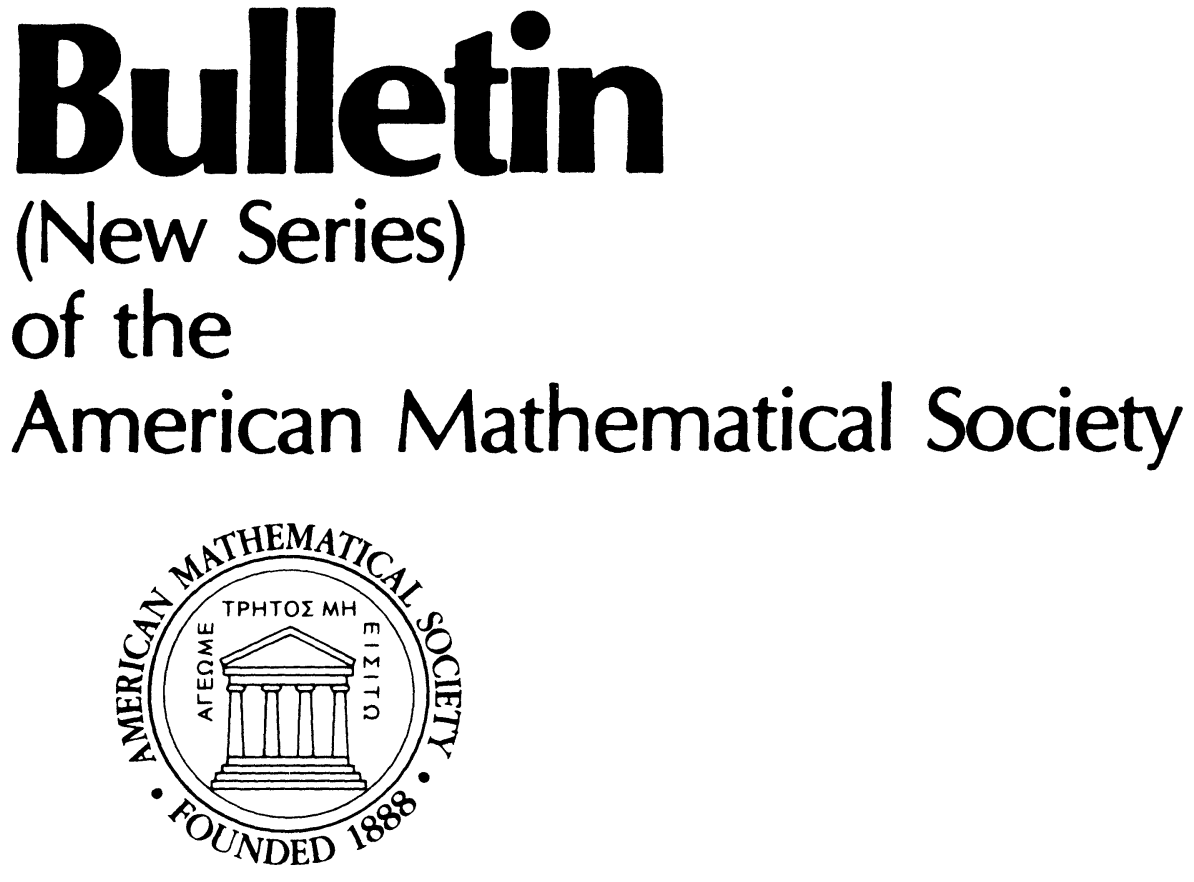

EDITORS

Hyman Bass, Research-Expository Articles

Edgar Lee Stout, Book Reviews

Wu-chung Hsiang, Research Announcements

\title{
April 1986
}

Volume 14, Number 2, Pages 159-326

Providence, Rhode Island USA

ISSN 0273-0979 


\section{BULLETIN (New Series) of the American Mathematical Society}

BULLETIN (New Series) contains articles of the types listed below. Information on Manuscript, Proof, and Copying can be found at the back of this journal.

\section{RESEARCH-EXPOSITORY PAPERS}

These are, by definition, papers which present a clear and insightful exposition of significant aspects of contemporary mathematical research. Gibbs lectures and retiring presidential addresses will be included in this section. Manuscripts should be submitted to Professor Hyman Bass, Department of Mathematics, Columbia University, New York, New York 10027.

\section{RESEARCH ANNOUNCEMENTS}

The purpose of this department is to provide quick publication of new and significant results of interest to mathematicians. Collectively, the editorial board for research announcements will choose approximately fifteen papers for each issue of the BULLETIN. The deadlines for submission are August 15 for the January issue, November 1 for the April issue, February 1 for the July issue and May 1 for the October issue. Announcements are limited to 125 typed lines of 70 spaces each. Authors should send five copies of each manuscript (to speed the decision process) to Wu-chung Hsiang, Executive Editor for Research Announcements, Department of Mathematics, Fine Hall, Princeton University, Princeton, New Jersey 08544. Authors are requested to include an introductory paragraph intelligible to the nonexpert stating the nature and significance of their results. Sketches and/or ideas of proof must be included.

\section{REVIEWS OF BOOKS ON ADVANCED MATHEMATICS}

Book Reviews should be sent to Professor Edgar Lee Stout, Department of Mathematics, University of Washington, Seattle, Washington 98185.

Subscription Information: BULLETIN (New Series) of the American Mathematical Society is published quarterly. Subscription prices for Volumes 14 and 15 (1986) are $\$ 148$ list, $\$ 118$ institutional member, $\$ 89$ individual member. The subscription price for members is included in the annual dues. A late charge of $10 \%$ of the subscription price will be imposed upon orders received from nonmembers after January 1 of the subscription year. Subscribers outside the United States and India must pay a postage surcharge of $\$ 8.00$; subscribers in India must pay a postage surcharge of $\$ 13.00$. Combination paper and microfiche subscription prices are $\$ 197$ list, $\$ 157$ institutional member. Microfiche of each issue will be mailed the fastest way before the camera copy is sent to the printer. Microfilm subscriptions may be purchased from University Microfilms International, 300 North Zeeb Road, Ann Arbor, MI 48106.

Back Number Information: Back number prices (per volume) for BULLETIN (New Series) Volume 1 are $\$ 60$ list, $\$ 48$ institutional member; for Volumes 2-9 $\$ 30$ list, $\$ 24$ institutional member; for Volumes 10-11 $\$ 38$ list, $\$ 30$ institutional member; for Volumes 12-13 $\$ 90$ list, $\$ 72$ institutional member. Back number prices (per volume) of Volumes 1-84 for the BULLETIN of the American Mathematical Society which ceased publication in 1978 are $\$ 60$ list, $\$ 48$ institutional member. Back volumes may be purchased on microfilm or microfiche from University Microfilms International, 300 North Zeeb Road, Ann Arbor, MI 48106.

Subscriptions and orders for publication should be addressed to the American Mathematical Society, P.O. Box 1571, Annex Station, Providence, RI 02901-1571. All orders must be accompanied by payment. Other correspondence should be addressed to the Society at P.O. Box 6248, Providence, RI 02940.

BULLETIN (New Series) of the American Mathematical Society (USPS 075640) is published quarterly by the American Mathematical Society at 201 Charles Street, Providence, RI 02904. Second-class postage is paid at Providence, Rhode Island and additional mailing offices. Postmaster: Send address changes to BULLETIN, American Mathematical Society, P.O. Box 6248, Providence, RI 02940.

Copyright (C) American Mathematical Society 1986. All rights reserved.

Information on Copying and Reprinting can be found at the back of this journal.

Printed in the United States of America

The paper used in this book is acid-free and falls within the guidelines established to ensure permanence and durability. 